\title{
Cinco novas espécies de Xyris (Xyridaceae) da Serra do Cipó, Minas Gerais, Brasil
}

\author{
Five new species of Xyris (Xyridaceae) from Serra do Cipó, Minas Gerais, Brazil
}

Maria das Graças Lapa Wanderley ${ }^{1}$

\begin{abstract}
Resumo
São descritas e ilustradas cinco novas espécies de Xyris (Xyridaceae): X. anamariae Wand. \& Kral, $X$. fredericoi Wand., X. kralii Wand., X. nanuzae Wand. e X. piranii Wand., endêmicas da Serra do Cipó, na Cadeia do Espinhaço de Minas Gerais. Xyris fredericoi, conhecida popularmente como "abacaxi-dourado", é uma das espécies com maior potencial ornamental da família, sendo proposta a inclusão da mesma na lista das espécies ameaçadas da flora brasileira.
\end{abstract}

Palavras-chave: Cadeia do Espinhaço, campos rupestres, sempre-vivas.

\begin{abstract}
Five new species of Xyris (Xyridaceae) are described and illustrated: X. anamariae Wand. \& Kral, X. frederico $i$ Wand., X. kralii Wand., X. nanuzae Wand. and X. piranii Wand. They are endemic to Serra do Cipó in the Espinhaço mountain range, Minas Gerais state, Brazil. Xyris fredericoi, popularly known as "abacaxi-dourado" ("golden pineapple"), is one of the most ornamental species in the family and should be considered endangered.
\end{abstract}

Key words: Espinhaço Range, campos rupestres, sempre-vivas.

\section{Introdução}

Xyridaceae compreende cinco gêneros, sendo Xyris Gronov.exL. o maior, com cerca de 390 espécies, seguido por Abolboda Humb. \& Bonpl., com 23 espécies; Orectanthe Maguire, com duas, e Aratitiyopea Steyerm. \& P.E. Berry e Achlyphila Maguire \& Wurdack, ambos monoespecíficos (Kral 1988; Wanderley 1992; Wanderley 2003; Campbell 2005, Campbell et al. 2009; Wanderley \& Silva 2009).

Xyridaceae tem distribuição essencialmente tropical e subtropical, com poucas espécies de Xyris ocorrendo na África, América do Norte e Australásia. A grande maioria das espécies de Xyris e todas as espécies dos demais gêneros da família apresentam distribuição na América do Sul, sendo o Brasil e o Escudo das Guianas os dois maiores centros de diversidade da família (Campbell 2004, 2005).

Smith \& Downs (1968), no estudo das Xyridaceae brasileiras, referiram 115 espécies de Xyris para o Brasil, porém levantamentos recentes indicam a ocorrência de mais de 179 espécies deste gênero, sendo 73\% endêmicas, confirmando a grande diversidade de Xyris no Brasil. O segundo centro de diversidade é o Escudo das Guianas, que segundo Campbell (2004, 2005), apresenta cerca de 90 espécies, sendo $65 \%$ endêmicas.

No Brasil, o gênero Xyris ocorre predominantemente nos campos rupestres, sendo bem representado na Cadeia do Espinhaço, que se estende ao longo dos estados de Minas Gerais e Bahia. Esta região apresenta um reconhecido índice de endemismo em várias famílias de Angiospermas, dentre elas Xyridaceae (Giulietti et al.1987; Giulietti \& Pirani 1988; Wanderley 1992).

A descrição crescente de espécies novas de Xyris para o Brasil tem contribuído para o aumento significativo do número de espécies brasileiras deste gênero, sendo a maioria procedente da região da Cadeia do Espinhaço de Minas Gerais, onde ainda existem muitas lacunas de coleta e de conhecimento taxonômico da família. Com o andamento da revisão taxonômica de Xyris para o Neotrópico, várias espécies inéditas são continuamente 
descobertas e descritas, ampliando para 400 espécies o número de espécies do gênero, cinco das quais, procedentes da Serra do Cipó, na Cadeia do Espinhaço de Minas Gerais, são aqui descritas e ilustradas.

\section{Material e Métodos}

Este trabalho faz parte do projeto Flora da Serra do Cipó, Minas Gerais, Brasil, coordenado pela Universidade de São Paulo (Giulietti et al. 1987). As coletas do projeto fazem parte da Coleção Flora da Serra do Cipó, registradas nas etiquetas de herbário sob a sigla CFSC. A maior parte deste material encontrase depositado nos Herbários SP, SPF e UEC. As exsicatas de Xyridaceae pertencentes à coleção CFSC foram a base principal para os estudos taxonômicos deste gênero, realizados por Wanderley (1992), assim como para o desenvolvimento do presente trabalho. Foram examinadas, além das coleções acima referidas, várias exsicatas pertencentes a diversos herbários nacionais e estrangeiros (B, BHCB, HB, K, M, NY, P, R, $\mathrm{RB}$, US e VDB), incluindo materiais-tipos de espécies afins às espécies novas aqui descritas, visando à confirmação das determinações e os comentários sobre as relações taxonômicas entre elas.

Para a elaboração do presente trabalho foram utilizados os procedimentos usuais em trabalhos de taxonomia, realizando-se um intenso trabalho de campo, o que permitiu importantes observações das populações e da variabilidade morfológica das espécies estudadas. Foram consultadas bibliografias específicas sobre o gênero Xyris, destacando-se Smith \& Downs (1968) e Wanderley (1992), assim como as descrições originais de espécies consideradas relacionadas às novas espécies.

\section{Resultados e Discussão}

Xyris anamariae Wand. \& Kral, sp. nov. Tipo: BRASIL. MINAS GERAIS: Santana do Riacho, Rodovia Belo Horizonte-Conceição do Mato Dentro, km 137, 15.VIII.1979, M.G.L. Wanderley CFSC 5616 (holótipo SP!; isótipos SPF!, NY!).

Fig. 1

Rhizomata internodiis dispersis. Folia disticha; vagina marginibus dense ciliatis ad glabrescentes; lamina filifomis ad subcylindricam, dense pilosa. Scapus filiformis. Spica pauciflora, c. 5-floribus; bracteae steriles 4, maculis castaneorubescentes manifestae, fortiter carenatae, carena dense pilosa, apice excurrenti; sepala lateralia inclusa, connata usque 1/3 longitudinis. Placentatio centrali-libera. Capsula paucis seminibus munita.
Ervas perenes, cespitosas, base da planta estreita. Raízes fibrosas. Rizoma ca. $3 \mathrm{~cm}$ compr., entrenós espaçados. Folhas dísticas, eretas, 3,5-7 cm compr.; bainha ca. 3-4 mm larg., base pouco alargada, castanho-escura, pilosa a glabrescente, margem escabro-ciliada; lígula ausente; lâmina filiforme a subcilíndrica, 1-1,5 cm compr., ápice agudo, atenuado, margem densamente ciliada a glabrescente, superfície estriada. Espata 3,5-6,5 cm compr., conduplicada, carenada, lâmina curta, ca. 3 $\mathrm{mm}$ compr., ápice ciliado. Escapo 7,5-14 cm compr., filiforme, ca. $1 \mathrm{~mm}$ larg., no ápice mais alargado e elipsóide, 1- ou 2-costelado, costelas ciliadas. Espiga pauciflora, ca. 5 flores, elipsóide, 7-8 ×2,5-4 mm, eixo da inflorescência curto, ca. $2 \mathrm{~mm}$ compr.; brácteas estéreis 4 , coriáceas, ovado-lanceoladas, 4-5,5 ×2-2,5 $\mathrm{mm}$, as duas mais externas pouco menores que as adjacentes, rugulosas, castanho-escuras, com mácula castanho-avermelhada evidente, fortemente carenadas, carena excurrente e densamente pilosa, margem pouco lacerada a inteira; brácteas florais coriáceas, pouco distintas das estéreis, ovadas, 6-7× 2-2,5 mm, castanhas, ápice piloso; sépalas laterais inclusas, concrescidas até $1 / 3$ do comprimento, lanceoladas, suberetas, ca. $6,5 \times 1 \mathrm{~mm}$, subequilaterais, carena densamente pilosa em direção ao ápice, tricomas avermelhados; pétala ca. 10,5 mm compr., lobo ovado, ca. $6,5 \times 2 \mathrm{~mm}$; estaminódios bífidos, ca $2 \mathrm{~mm}$ compr.; estames ca. $2 \mathrm{~mm}$ compr., antera oblonga, amarela; estilete ca. $6 \mathrm{~mm}$ compr., ramos ca. 2,5 mm compr., estigmas pouco alargados. Placentação centrallivre, óvulos com funículos alongados. Cápsula ovóide, ca. 3,5 mm compr.; sementes elipsóides, poucas, ca. 0,5 mm compr., estriadas.

Material examinado: MINAS GERAIS: Santana do Riacho, rodovia Belo Horizonte-Conceição do Mato Dentro, km 126, 3.IX.1972, J. Semir \& M. Sazima CFSC 3325 (SP); km 135, 25.IV.1978, G. Martinelli 4233 (RB); km 136, 5.VII.1978, M.G.L. Wanderley CFSC 5502 (SP); km 132, 31.VII.1985, R. Kral \& E.A. Lopes 72966(SP, VDB); $\mathrm{km} \mathrm{132,1.VIII.1985,} \mathrm{R.} \mathrm{Kral} \mathrm{\&} \mathrm{E.A.} \mathrm{Lopes} 72974$ (SP, VDB); km 122, Retiro da Fazenda Palácio, 11.VII.1987, M.G.L. Wanderley et al. CFSC 10681 (SP); km 128, 11.VII.1987, M.G.L. Wanderley et al. CFSC 10395(SPF); Parque Nacional da Serra do Cipó, Córrego da Água Preta, Serra da Salitreira, 12.VII.1987, M.G.L. Wanderley et al. CFSC 10683 (SP); 7 km além da bifurcação em direção ao Morro do Pilar, 30.VIII.1988, N.L. Menezes et al. CFSC 11193 (SPF); km 135, 25.IV.1978. G. Martinelli 4233 (RB).

O epíteto específico desta nova espécie foi dado em homenagem à Dra. Ana Maria Giulietti Harley, especialista em Eriocaulaceae e grande conhecedora da flora dos campos rupestres brasileiros. 

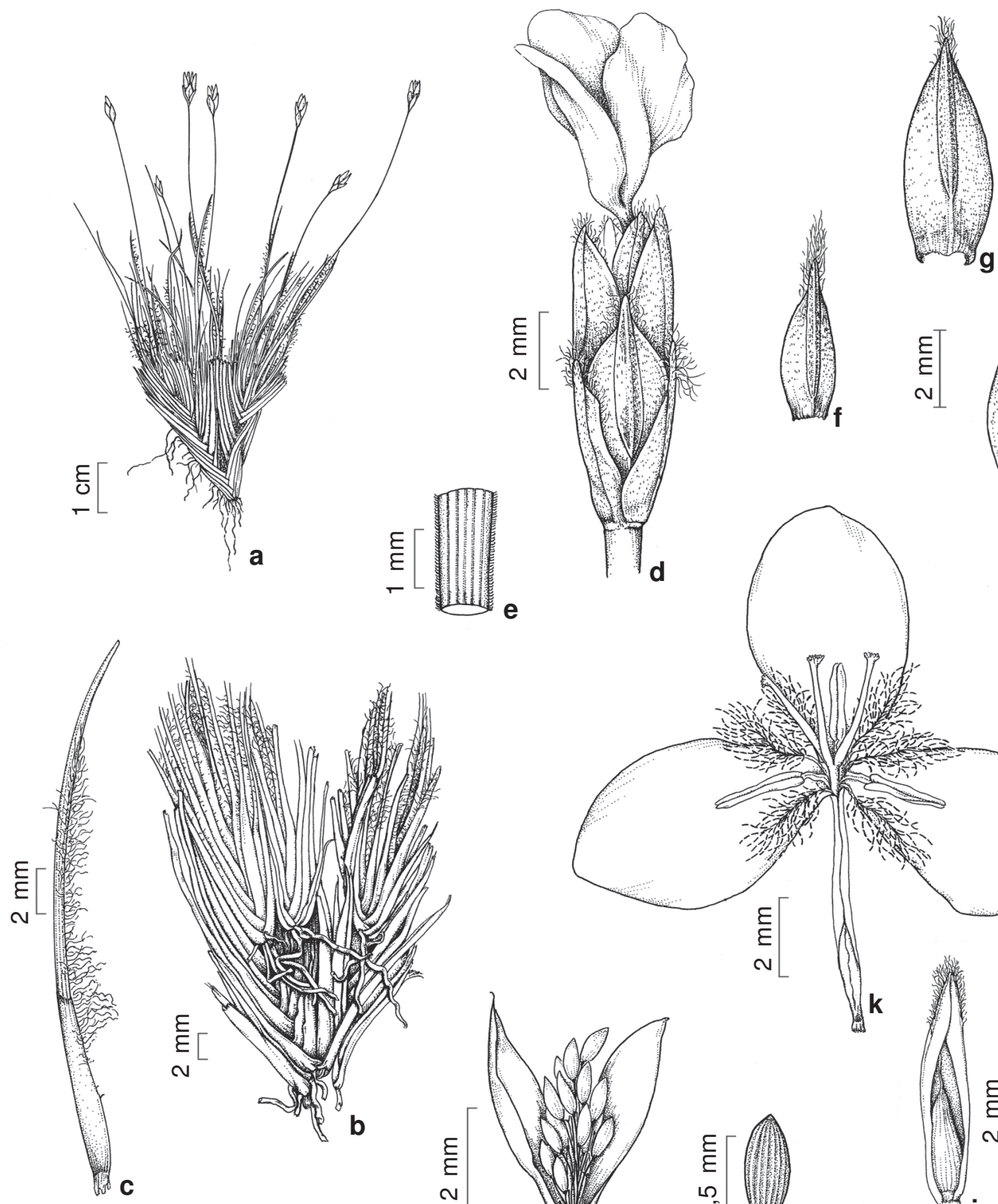

$$
\text { Nforomsi }
$$
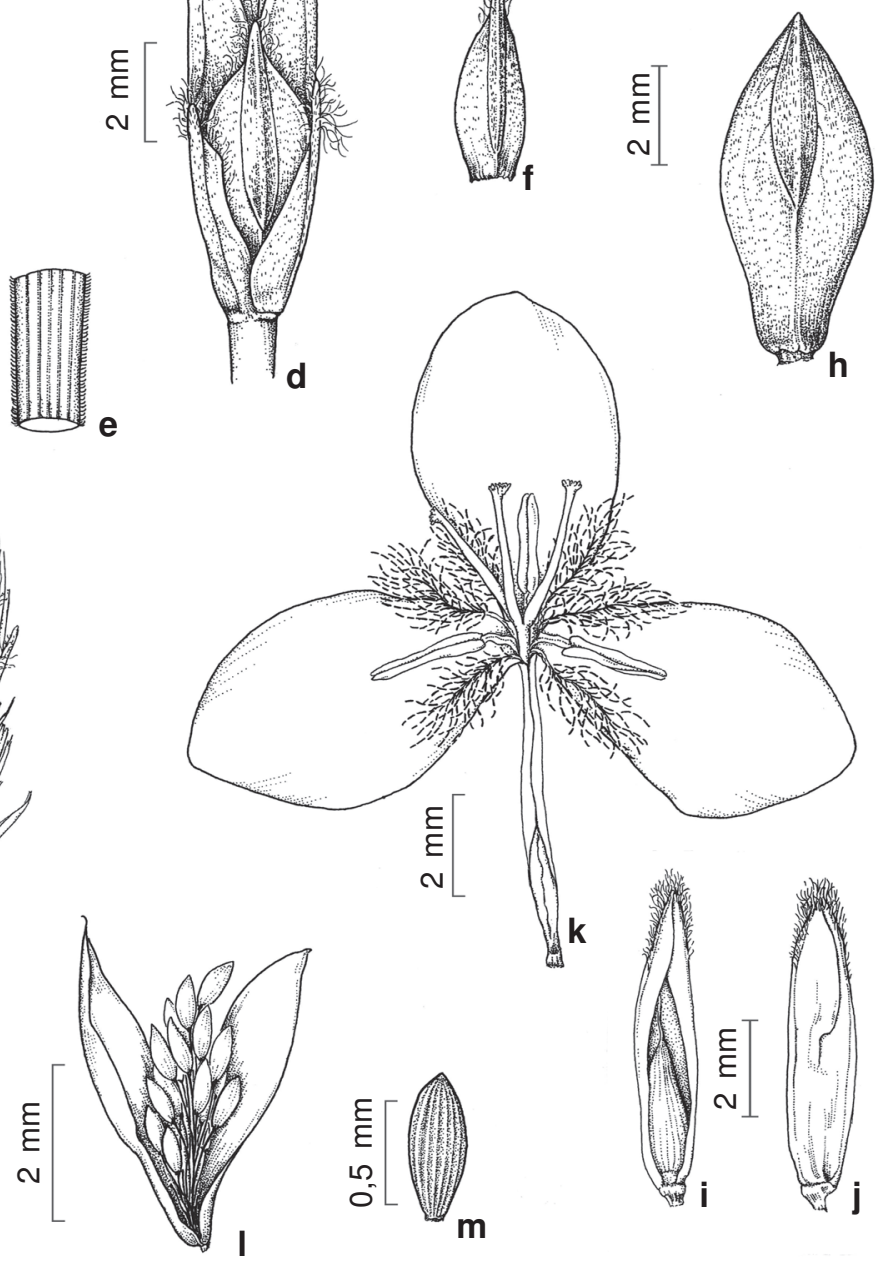

Figura 1 -Xyris anamariae - a. hábito; b. detalhe da base da planta, mostrando rizoma com entrenós espaçados; c. folha com densa pilosidade; d. espiga com uma flor aberta; e. parte superior do escapo; f-g. brácteas estéreis, mostrando carena e ápice excurrente; h. bráctea floral; i-j. sépalas laterais concrescidas; $k$. flor aberta sem as sépalas, com pétalas, androceu e gineceu; 1 . fruto aberto, mostrando placentação central-livre e sementes; m. semente ( Wanderley CFSC 5616).

Figura 1 - Xyris anamariae - a. habit; b. base of the plant, rhizome with spaced internodes; c. leaf with dense pilosity; d. spike with open flower; e. scape apex; f-g. sterile bracts, with keel and excurrent apex; h. floral bract; i-j. connate lateral sepals; k. open flower with petals, androecium, gynoecium, without sepals; 1 . open capsule, with central-free plancentation and seeds; m. seed (Wanderley CFSC 5616). 
Xyris anamariae foi registrada até o presente apenas para a Serra do Cipó, sendo encontrada nos locais brejosos dos campos rupestres. Floresce e frutifica entre os meses de abril e setembro, com maior pico de floração em julho.

Xyris anamariae é bem distinta da maioria das espécies ocorrentes na região da Serra do Cipó, sendo caracterizada pelas densas touceiras formadas pela presença de rizomas com entrenós alongados e rizomas horizontais curtos. As folhas são tipicamente dísticas e flabeladas, com lâmina filiforme a subcilíndrica, pilosa a glabrescente. As espigas paucifloras com brácteas providas de mancha conspícua e carena excurrente são também características peculiares desta espécie. A espécie apresenta afinidades morfológicas com $X$. calostachys Poulsen, $X$. insignis L.A. Nilsson e $X$. pilosa Kunth, compartilhando com elas as brácteas carenadas de ápice excurrente e, em geral, densamente pilosas, e as bainhas foliares ciliadas. Como X. pilosae $X$. calostachys, X. anamariae também apresenta bainhas com tricomas alongados, ao passo que, em $X$. insignis os tricomas são mais curtos. Xyris anamariae pode ser facilmente reconhecida dentre essas três espécies pelo porte menor, escapo mais curto, com até $14 \mathrm{~cm}$ de altura, enquanto nas outras duas o escapo varia de $27 \mathrm{a} 40 \mathrm{~cm}$ de altura. As espigas em $X$. anamariae são paucifloras, com cerca de cinco flores, enquanto as espécies afins apresentam de dez a mais flores. Outras características que distinguem estas espécies são a presença de sépalas concrescidas e a placentação central-livre em $X$. anamariae, enquanto que nas outras duas espécies as sépalas são livres e a placentação é basal. Brácteas com carena conspícua e excurrente, sépalas concrescidas e placentação central-livre também são encontradas em $X$. seubertii L.A. Nilsson e $X$. archeri L.B. Sm. \& Downs, as quais diferem prontamente de $X$. anamariae pelas folhas com lâmina achatada e glauca e espigas com mais de cinco flores.

Xyris fredericoi Wand., sp. nov. Tipo: BRASIL. MINAS GERAIS: Santana do Riacho, estrada Belo Horizonte-Conceição do Mato Dentro, Parque Nacional, Serra da Salitreira, 12.VII.1987, M.G.L. Wanderley \& F. Wanderley CFSC 11059 (holótipo SP!; isótipos SPF!, RB!). $\quad$ Fig. 2

Rhizomata robusta, internodiis brevibus. Folia vaginis amplificatis, marginibus glabris et membranaceis, superficie inconspicue rugulosa; laminae marginibus scabro-ciliatis. Scapus 95-200 cm longus, cylindricus ad trigonum, 1-multi-costatus, costae scabro-ciliatae. Spica multiflora, 100-125- floribus, robusta, globosa, bracteae steriles c. 40, triangulari-lanceolatae, reflexae ad fortiter spirales, castaneo-luteae ad atro-castaneae; bracteae fertiles ovato-lanceolatae, apice recurvato; sepala lateralia $c .13 \mathrm{~mm}$ longa. Placentatio basalis, funiculis elongatis.

Ervas perenes, cespitosas, base da planta pouco alargada. Raízes espessas. Rizoma desenvolvido, robusto, com entrenós curtos. Folhas dísticas a subdísticas, 56-75 cm compr.; bainha 5-10 cm larg. na base fortemente alargada, castanho-escura apenas na base, estriada, margem glabra, membranácea; lígula ausente; lâmina achatada, 18-20 × 1,5-2 cm, ápice agudo, margem escabro-ciliada, superfície levemente estriada. Espata 50-77 cm compr., conduplicada, 3-costelada, costelas escabras, lâmina curta, ca. $3 \mathrm{~mm}$ compr., ápice atenuado. Escapo 0,95-2 m compr., robusto, cilíndrico a trígono, 4-5 mm larg., 1-multicostado, costas escabras. Espiga multiflora, 100-125 flores, robusta, globosa, 2,5-3,5 × 3-4 cm, eixo da inflorescência alongado, ca. 1,5 cm; brácteas estéreis numerosas, ca. 40, em geral recurvas a espiraladas, triangular-lanceoladas, $2-3 \times 4-5 \mathrm{~cm}$, castanho-amareladas a castanho-escuras, sem mácula, margem pouco distinta, mais clara e submembranácea; brácteas florais semelhantes às brácteas estéreis, porém gradativamente menores para o ápice, superfície rugulosa, ovadolanceoladas, 1,5-2,0 ×ca. $4 \mathrm{~cm}$, margem lacerada, membranácea; sépala anterior membranácea, amarelada; sépalas laterais inclusas, livres, lanceoladas, ca. $1,3 \times 0,2 \mathrm{~cm}$, inequilaterais, carenadas, carena esparsamente ciliada; pétalas ca. 2 cm compr., lobo ovado, ca.1 cm compr.; estaminódios pilosos, pedicelados; estames ca. $5 \mathrm{~mm}$ compr., antera sagitiforme, amarela; estilete 1,4-1,8 cm compr., ramos 4-5 mm compr., estigmas alargados. Placentação basal, funículos alongados. Cápsula obovóide, ca. 4 mm compr.; sementes elipsóides, ca. 1,3 mm compr., reticuladas.

Material examinado: MINAS GERAIS: Santana do Riacho, estrada Belo Horizonte-Conceição do Mato Dentro, Parque Nacional da Serra do Cipó, 12.VII.1987, M.B. Horta 154 (BHCB); Parque Nacional da Serra do Cipó, Serra das Bandeirinhas, 9.IX.1987, M.G.L. Wanderley et al. 10703 (SP); próximo à nascente do Rio Preto, 5.VII.1989, M.G.L. Wanderley et al. 11561 (SP). Material adicional examinado: Xyris cipoensis MINAS GERAIS: Santa Luzia, Serra do Cipó, 6.VII.1936, W.A. Archer \& H.L. Mello-Barreto 4914 (holótipo US; isótipo RB); X. coutensis-MINAS GERAIS: Couto de Magalhães, Chapada do Couto, 17.VII.1984, 


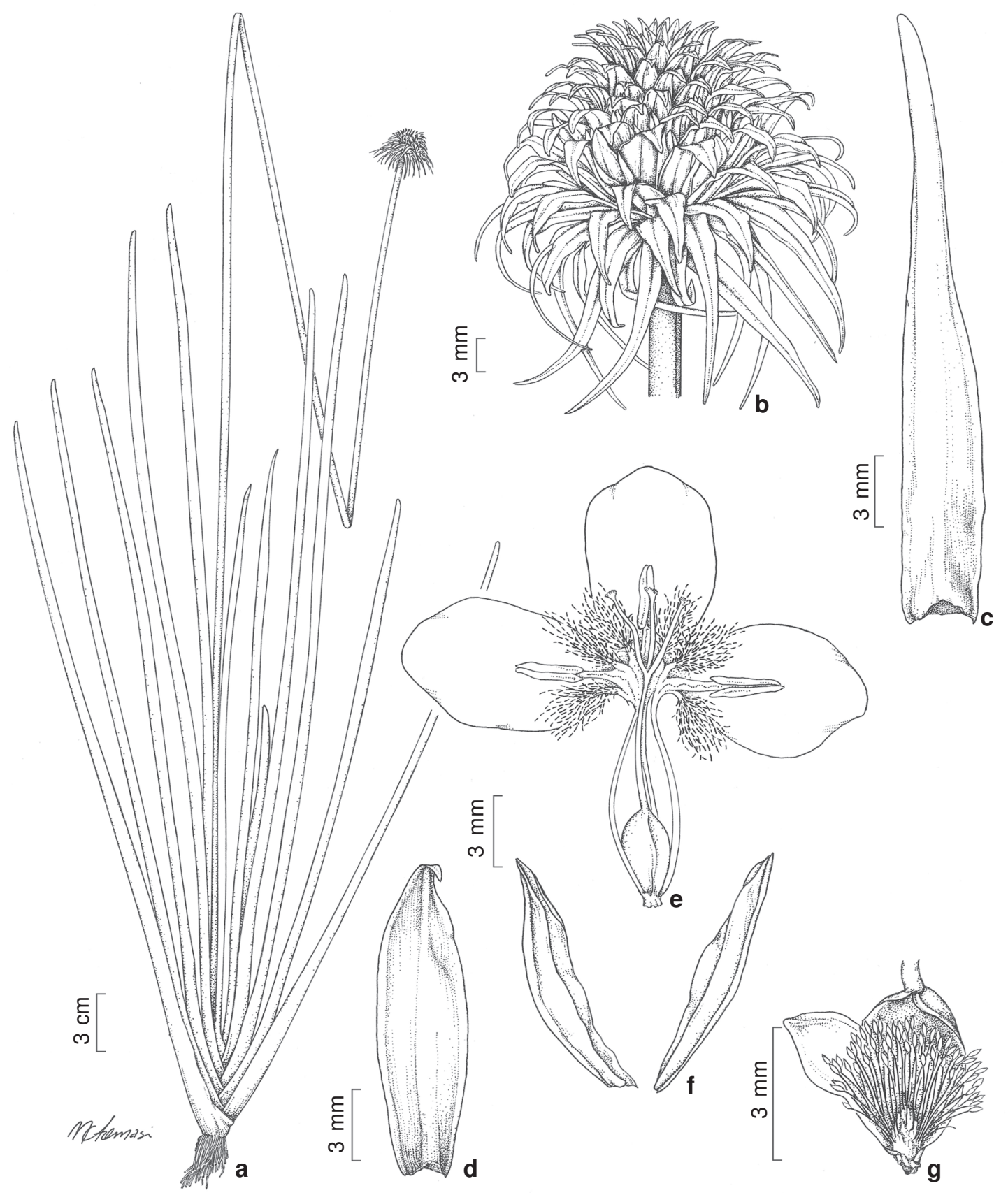

Figura 2 - Xyris fredericoi -a. hábito; b. espiga com numerosas brácteas; c.bráctea estéril; d. bráctea floral; e. flor aberta sem as sépalas, com corola, gineceu e androceu; f. sépalas laterais livres; g. ovário, mostrando placentação basal; óvulos com funículos longos ( Wanderley CFSC 11059).

Figura 2 -Xyris frederico - a. habit; b. spike with numerous bracts; c. sterile bract; d. floral bract; e. open flower with corolla, gynoecium and androecium, not showing sepals; f. free lateral sepals; g. ovary, basal placentation; ovules with long funicules (Wanderley CFSC 11059). 
M.G.L.Wanderley et al. 707 (holótipo SP; isótipos K, NY, SPF); X. hystrix - MINAS GERAIS: Tejuco, Serra Frio, A.C. Martius s.n. (holótipo M); Xyris nigricans - MINAS GERAIS: Alto Itacolomi, 25.VI.1884, A. Glaziou 15513 (holótipo US; isótipo RB).

O epíteto específico foi dado em homenagem ao Sr. Frederico Wanderley, pelo grande apoio ao desenvolvimento dos estudos taxonômicos das Xyridaceae da Serra do Cipó e pela participação na coleta desta espécie.

Xyris fredericoi é endêmica da Serra do Cipó, estendendo-se até a Serra da Bandeirinha nos limites do Parque Nacional da Serra do Cipó. Habita locais brejosos dos campos rupestres, próximos a córregos. As coletas dos indivíduos em floração foram efetuadas entre os meses de julho e agosto e em frutificação em setembro.

Esta espécie forma juntamente com Xyris cipoensis L.B. Sm. \& Downs, X. coutensis Wand. \& Cerati, $X$. hystrix Seubert e $X$. nigricans L.A. Nilsson um grupo de espécies bem característico e endêmico da Cadeia do Espinhaço de Minas Gerais. Estas espécies destacam-se especialmente pelas espigas vistosas e pelas plantas de médio a grande porte, formando um grupo de sempre-vivas, por manterem aspecto de vivas mesmo após a colheita. Por estas características estão entre as principais espécies de sempre-vivas de Xyris, sendo usadas em arranjos e ramalhetes para decoração de interior. O tamanho do escapo nestas espécies varia desde $40 \mathrm{~cm}$ até cerca de $2 \mathrm{~m}$ de altura, com $X$. fredericoi atingindo a maior altura dentre elas, representando a espécie com maior registro de altura para o gênero. Xyris hystrix apresenta altura média de $60 \mathrm{~cm}$ a 1,30 $\mathrm{m}$, sendo os menores exemplares destas semprevivas representados nas outras três espécies $(X$. cipoensis, $X$. coutensis e $X$. nigricans), cujas alturas variam em torno de 40 e $70 \mathrm{~cm}$. Entretanto, grandes variações na altura da planta são observadas em todas estas espécies. A nova espécie, além de possuir maior porte, apresenta escapo mais robusto e em geral multicostado, enquanto as demais apresentam escapo sem costelas a 3-costelado.

As espigas vistosas destas espécies são, em geral, globosas, multifloras, com 40 a mais de 120 flores por espiga e numerosas brácteas estéreis formando um envoltório bastante ornamental. Xyris fredericoi destaca-se dentre as espécies afins pelas espigas maiores e maior número de brácteas estéreis (100-125 flores e ca. 40 brácteas vs. 50-80 flores e 20-30 brácteas). As brácteas são em geral estreito-lanceoladas, recurvas a fortemente espiraladas (X. cipoensis, X. fredericoi,
$X$. hystrix e X.nigricans) e variam de o castanhoclaro, coloração bem característica na maior parte dos representantes de $X$. fredericoi, até o castanhoescuro a negro, predominante nas demais espécies. Xyris coutensis distingue-se das demais espécies acima referidas pelas brácteas estéreis castanhoescuras a negras, oblongas a oval-lanceoladas, não espiraladas, com apenas o ápice recurvo.

Um conjunto de características, como espigas vistosas e multifloras, invólucro de brácteas estéreis e placentação basal com óvulos de funículos tipicamente alongados, torna as espécies deste grupo bem delimitado em relação à grande maioria das espécies do gênero. As características vegetativas também vêm se revelando de importância na separação de espécies no gênero Xyris, servindo para o reconhecimento de espécies mesmo em estado vegetativo. Nesse grupo, em particular, a bainha fortemente transverso-rugulosa e castanho-arroxeada em toda sua extensão são características diagnósticas de $X$. cipoensis, distinguindo-a das demais espécies do grupo mesmo no exame das exsicatas de herbário. As demais espécies apresentam folhas com bainhas que variam de lisa, estriada a tuberculada e de coloração castanha apenas na base.

Xyris fredericoi é conhecida popularmente como "abacaxi-dourado", pelo fato da espiga apresentar numerosas brácteas fortemente imbricadas, algumas vezes de coloração amarelodourada, dando o aspecto de uma coroa semelhante a do abacaxi, das Bromeliaceae (Giulietti et al. 1996). Pelo aspecto ornamental que a espécie apresenta, além da ocorrência de exemplares de grande porte, esta espécie está entre as sempre-vivas mais ornamentais e de maior valor comercial. O intenso extrativismo que vinha sofrendo há alguns anos levou a grande redução das populações desta espécie, cujo registro até o momento é para o Parque Nacional da Serra do Cipó. De modo semelhante, $X$. coutensis, espécie conhecida por pequenas populações na Chapada do Couto, no Parque Estadual do Rio Preto e possivelmente de ocorrência em outras serras mineiras, está incluída na lista das espécies ameaçadas de Minas Gerais (Mendonça \& Lins 2000), recomendando-se a inclusão de $X$. fredericoi na mesma categoria da anterior, ou seja Criticamente em Perigo (CR). Estas duas espécies são conhecidas até o momento por pequenas populações em áreas restritas, além de terem sido submetidas a intenso extrativismo, o que resultou na diminuição de suas populações naturais. 
Exemplares das mesmas, assim como de outras sempre-vivas, são ainda encontrados em forma de arranjos florais em centros de vendas na cidade de Diamantina, em Minas Gerais.

Xyris cipoensis e $X$. nigricans também fazem parte da lista das espécies ameaçadas de Minas Gerais na categoria Em Perigo (EN) (Mendonça \& Lins 2000), entretanto nenhuma das espécies de sempre-vivas acima mencionadas está incluída na Lista Oficial de espécies ameaçadas do MMA. Uma melhor avaliação da categoria de ameaça destas espécies deve ser feita, uma vez que as mesmas preenchem alguns critérios propostos pela IUCN, sendo espécies raras, de área de ocorrência relativamente restrita e que sofrem grande pressão de extrativismo pelo valor ornamental, mesmo ocorrendo em Unidades de Conservação.

Xyris kralii Wand., sp. nov. Tipo: BRASIL. MINAS GERAIS: Parque Nacional da Serra do Cipó, Serra das Bandeirinhas, caminho para a Cachoeira das Flores, 9.IX.1987, M.G.L. Wanderley, O. Yano, T.B. Cavalcanti, V. Scatena, A.L. Dokkedal \& J. Prado CFSC 10701 (holótipo SP!; isótipo SPF!). Fig. 3

Rhizoma internodiis plusminusve longis. Folia vaginis amplificatis, orbicularia, atrocastanea, nitentia, marginibus glabris; lígula acuta; laminae leviter compressae ad cylindricas, apice acuminato, glabrae, superficie fortier nervatae, transverse rugulosae. Spica multiflora, 15-floribus, bracteae steriles 22, maculis et carenis munitae; sepala lateralia libera, naviculares, carena fimbriata. Placentatio centrali-libera.

Ervas perenes, cespitosas, base da planta subbulbiforme. Raízes fibrosas. Rizoma desenvolvido, algumas vezes subvertical. Folhas dísticas a espiraladas, eretas, 15-35 cm compr.; bainha ca. 3 cm compr., arredondada, castanho-escura, brilhante, margem glabra, mais clara; lígula presente, aguda, ca. $3 \mathrm{~mm}$ compr.; lâmina pouco comprimida a cilíndrica, ca. $15 \times 0,1 \mathrm{~cm}$, ápice longo-acuminado, margem glabra, fortemente nervada. Espata ca. 8,5 cm compr., conduplicada, superfície sulcada, lâmina curta, ca. 1-3 mm compr., acuminada. Escapo 15$40 \mathrm{~cm}$ compr., cilíndrico, 2-costelado a irregularmente 3 -costelado, costelas glabras. Espiga multiflora, ca. 15 flores, elipsóide a subglobosa, base atenuada, 6-12 ×3,5-5 mm; brácteas densamente imbricadas, as estéreis numerosas (ca. 22), elípticas, oblongas a obovadas, $2-4 \times 1-3 \mathrm{~mm}$, as quatro mais externas distintamente menores, castanhas, com mácula ovalada, esverdeada a vermelho-castanha, distinta, carenadas e nervadas, margem pouco distinta, glabrescentes no ápice; brácteas florais obovadas a clavadas, ca. $4 \times 2 \mathrm{~mm}$, margem ciliado-laciniada e avermelhada em direção ao ápice; sépalas laterais livres, inclusas a exsertas, curvas em direção ao ápice, naviculares, ca. $5 \times 1 \mathrm{~mm}$, inequilaterais, carena larga, ciliado-fimbriada, tricomas longos e avermelhados, ápice agudo, excurrente; pétala ca. $9 \mathrm{~mm}$ compr., lobo ovalado, 4-5 × ca. $4 \mathrm{~mm}$, estaminódios bifurcados, pilosos, tricomas longos e moniliformes; estames ca. 2,5 mm compr., antera sagitiforme, amarela; ovário oblongo, estilete ca. $9 \mathrm{~mm}$ compr., ramos ca. 2,5 mm compr., estigmas pouco alargados. Placentação central-livre, funículos longos. Cápsula obovóide; sementes poucas, fusiformes, reticuladas.

Material examinado: BRASIL. MINAS GERAIS: Santana do Riacho, rodovia Belo Horizonte-Conceição do Mato Dentro, Capivarinha, 6.VIII.1933, H.L.Mello Barreto, 4354 (RB); km 98, 4.VII.1978, M.G.L. Wanderley CFSC 5489 (SP); km 137, 15.VII.1979 M.G.L. Wanderley CFSC 5612 (SP); Parque Nacional da Serra do Cipó, Serra das Bandeirinhas, 9.IX.1987, M.G.L. Wanderley et al. CFSC 10700 (SP, SPF); 9.IX.1987, M.G.L. Wanderley et al. CFSC 10702 (SP, SPF); Riacho Grande que vai para a Cachoeira da Farofa, 10.IX.1987, M.G.L. Wanderley et al. CFSC 11063 (SP, SPF).

O nome da espécie é uma homenagem ao Dr. Robert Kral, grande especialista em Xyridaceae e parceiro nos estudos na família.

Xyris kralii é endêmica dos campos rupestres de Minas Gerais, sendo registrada até o momento para a Serra do Cipó, ocorrendo na Serra da Bandeirinha. Os indivíduos em flor foram coletados entre os meses de julho e agosto e em fruto em setembro.

A espécie caracteriza-se pela presença de rizomas alongados e folhas cilíndricas, com lígula conspícua, estrutura que delimita claramente a bainha da lâmina, além da bainha bem marcante pela coloração castanho-escura e brilhante. Por estas características vegetativas a espécie está relacionada a Xyris filifolia L.A. Nilsson e $X$. teres L.A. Nilsson, espécies que se distribuem de Minas Gerais ao Rio Grande do Sul.

Semelhante a Xyris teres, a nova espécie também possui placentação central-livre, entretanto estas duas espécies são bem distintas e facilmente reconhecidas, apresentando $X$. teres plantas de maior porte, atingindo quase $1 \mathrm{~m}$ de altura $(v s . \mathrm{ca} .40 \mathrm{~cm}) \mathrm{e}$ espigas bem maiores (9-15 $\mathrm{mm}$ vs . 6-12 mm), globosas a ovóides (vs. elipsóides a subglobosas). Por outro lado, X. filifolia apresenta placentação basal (Wanderley et al. 2003), além de várias características vegetativas e florais que a distingue facilmente da nova espécie. 


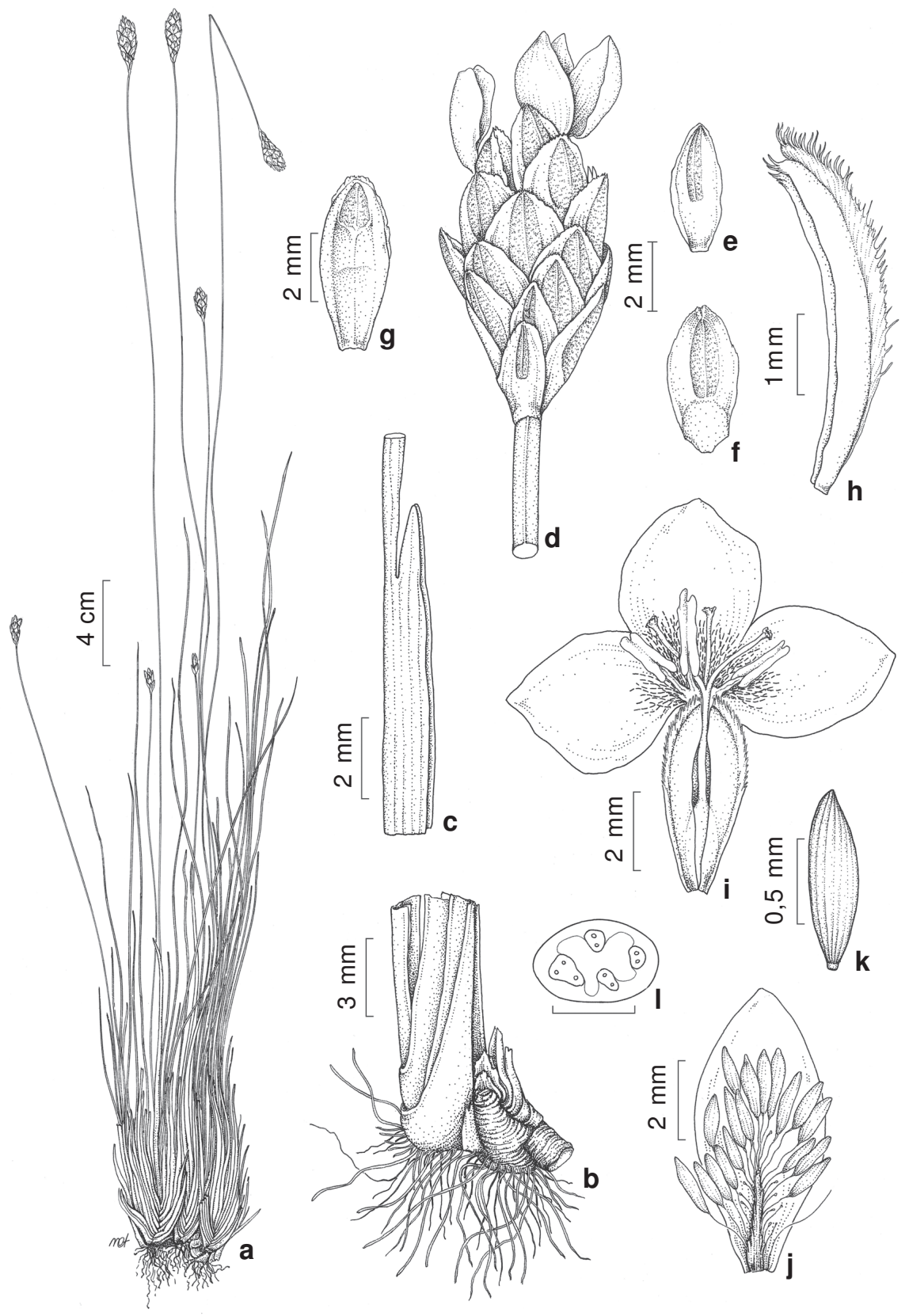

Figura 3 - Xyris kralii - a. hábito; b. base da planta, rizoma lateral robusto; c. detalhe da folha, mostrando parte da bainha com lígula aguda e base da lâmina cilíndrica; d. espiga; e-f. brácteas estéreis, nota-se área dorsal com mácula conspícua; g. bráctea floral com mácula conspícua; h. sépala lateral mostrando carena larga e ciliado-fimbriada; i. flor aberta, com sépalas, pétalas de lobos orbiculares, androceu e gineceu; j. fruto com uma das três valvas, eixo placentário central curto, com sementes de funículos longos; k. semente; 1 . corte transversal na base da lâmina foliar de contorno circular, mostrando os feixes vasculares (a-c Wanderley CFSC 11568; d-1 Wanderley CFSC 10700).

Figura 3 -Xyris kralii - a. habit; b. base of the plant, with lateral robust rhizome; c. leaf detail, showing sheath with acute ligule and cylindrical blade base; d. spike; e-f. sterile bracts, with conspicuous macula; g. floral bract with conspicuous macula; h. lateral sepal with ciliate-fimbriate large keel; i. open flower, with sepals, petals with orbicular lobes, androecium and gynoecium; j. capsule with three valves, short central axis, seeds with long funicules; k.seed; 1. cross section of leaf blade base, showing vascular bundles. (a-c Wanderley CFSC 11568; d-1 Wanderley CFSC 10700). 
Xyris nanuzae Wand., sp. nov. Tipo: BRASIL. MINAS GERAIS: Santana do Riacho, rodovia Belo Horizonte-Conceição do Mato Dentro, km 138, 15.VIII.1979, M.G.L. Wanderley CFCS 5614 (holótipo SP!; isótipo SPF!).

Fig. 4

Rhizomata aliquando internodiis elongatis.

Folia vaginis fortiter amplificatis, atro-castanea, glabra; lamina apice acuto et attenuato, falciformi, marginibus ciliatis, superficie transverse rugulosa ad costatam. Spica pauciflora, c. 6-floribus munita; bracteae sine maculis vel maculis inconspicuis; bracteae florales ciliato-fimbriatae apicem versus; sepala lateralia exserta, connata c. 1/3 longitudinis, aequilaterales, carena ampla, dense pilosa; petala lobo orbiculari. Placentatio centrali-libera.

Ervas perenes, cespitosas, base pouco alargada. Raízes delicadas. Rizoma com entrenós curtos a alongados. Folhas dísticas a subdísticas, eretas, paleáceas, (8-)10,5-32 cm compr.; bainha fortemente alargada, ca. 1 cm larg., castanha, margem membranácea, glabra; lígula inconspícua; lâmina linear, achatada, 6-21 × 2,5-4 cm, ápice agudo, falciforme, margem espessada, ciliada, superfície costelada, transversorugulosa. Espata 7-21 cm compr., conduplicada, paleácea, lâmina curta, ca. 2 mm compr. Escapo 22 $62 \mathrm{~cm}$ compr., subcilíndrico, levemente comprimido em direção ao ápice, 2-costelado, costelas ciliadas. Espiga pauciflora, ca. 6 flores, ovóide a subglobosa, 7-11 ×4-8 mm, eixo da inflorescência ca. 2 mm compr.; brácteas estéreis 4, ovadas a suborbiculares, 4-6×2,5$3,5 \mathrm{~mm}$, as duas mais externas distintamente menores, castanho-claras, máculas raramente presentes, rugulosas, margem inteira; brácteas florais subcoriáceas, oblongo-ovadas, ca. $7 \times 2,3 \mathrm{~mm}$, castanho-claras, ciliado-fimbriadas no ápice, tricomas curtos e vermelhos, margem membranácea, distinta; sépala anterior membranácea, esverdeada; sépalas laterais exsertas, concrescidas ca. 1/3 do comprimento, ca. 7 $\times 1,2 \mathrm{~mm}$, equilaterais, carena larga, densamente pilosa, tricomas vermelhos; pétalas ca. $1,3 \mathrm{~cm}$ compr, lobo orbicular, ca. $6 \times 6 \mathrm{~mm}$; estaminódios densamente pilosos, ca. $3 \mathrm{~mm}$ compr.; estames ca. $3 \mathrm{~mm}$ compr., antera linear, amarela; estilete ca. $9 \mathrm{~mm}$ compr., ramos ca. 3,8 mm, estigma alargado. Placentação centrallivre. Cápsula oblonga, 3-4 mm compr.; sementes estriadas, ca. 0,7 mm compr., fusiformes.

Material examinado: BRASIL. MINAS GERAIS: Santana do Riacho, rodovia Belo Horizonte-Conceição do Mato Dentro, km 127, 14.VIII.1979, M.G.L. Wanderley CFSC 5570 (SP); km 138, 14.VIII.1979,M.G.L. Wanderley CFSC 5542 (SP); km 132, 14.VIII.1979, M.C. Henrique, CFSC 5553 (SP); km 126, 15.VIII.1979, M.G.L. Wanderley
CFSC 5652 (SP); km 126, 16.VIII.1979,M.G.L. Wanderley CFSC 5709 (SP); estrada da Usina, 16.VIII.1979, M.G.L. Wanderley CFSC 5710 (SP); km 145, 31.VII.1985, R. Kral \& E.A. Lopes 72940 (SP, VDB); km 145, 31.VII.1985, R. Kral \& E.A. Lopes 72945 (SP, SPF, VDB); 1.VIII.1985, R. Kral \& E.A. Lopes 72976 (SP); Parque Nacional da Serra do Cipó, córrego da Água Preta, Serra da Salitreira, 12.VII.1987, M.G.L. Wanderley et al. CFSC 10684 (SP); 12.VII.1987, M.G.L. Wanderley et al. CFSC 10688 (SP); km 126, 5.VII.1989, M.G.L. Wanderley et al. CFSC 11563 (SP); km 139-140, 5.VII.1989, M.G.L. Wanderley et al. CFSC 11568 (SP).

O epíteto específico é uma homenagem à Dra. Nanuza Luiza de Menezes, especialista em Velloziaceae e uma das maiores conhecedoras da vegetação da Serra do Cipó.

Xyris nanuzae é uma espécie endêmica da Serra do Cipó, florescendo e frutificando entre os meses de julho e agosto.

Esta nova espécie é bem caracterizada pela presença de rizomas com entrenós curtos a alongados, folhas com lâminas paleáceas, costeladas, ápice agudo a falciforme e sépalas laterais equilaterais. A espécie apresenta afinidades morfológicas com Xyris seubertii, $X$. subsetigera Malme e $X$. archeri pela placentação central-livre e sépalas concrescidas. Entretanto, $X$. nanuzae é bem distinta destas três espécies pelo menor número de flores (ca. 6 vs. 8-10). As brácteas em $X$. nanuzae, em geral, não apresentam mácula, característica também ausente em $X$. archeri. Por outro lado, $X$. subsetigera e $X$. seubertii apresentam brácteas com mácula conspícua e fortemente carenadas. Esta última apresenta sépalas laterais densamente pilosas com tricomas vermelhos. As folhas glaucas presentes em $X$. seubertii a diferencia da nova espécie e das demais acima referidas.

Xyris piranii Wand. sp nov. Tipo: BRASIL. MINAS GERAIS: Santana do Riacho, rodovia Belo HorizonteConceição do Mato Dentro, km 140, 4.VII.1978, M.G.L. Wanderley CFSC 5478 (holótipo SP!; isótipo SPF!).

Fig. 5

Rhizomata internodiis brevibus. Folia apice attenuato, superficie striata. Bracteae steriles 4 , triangulares ad ovatas, atro-castaneae ad nigras, rugulosae, carena inconspicua, marginibus fortiter laceratis, apice obtuso; bracteae florales bracteis sterilibus similes. Sepala lateralia exserta; petala lobo oribiculari munita.

Ervas perenes, cespitosas, base da planta subbulbosa. Raízes delgadas. Rizoma com entrenós curtos. Folhas dísticas a espiraladas, (4,5-) 1-11 cm compr., eretas; bainha alargada, ca. 1,3 cm larg., glabra; lígula 


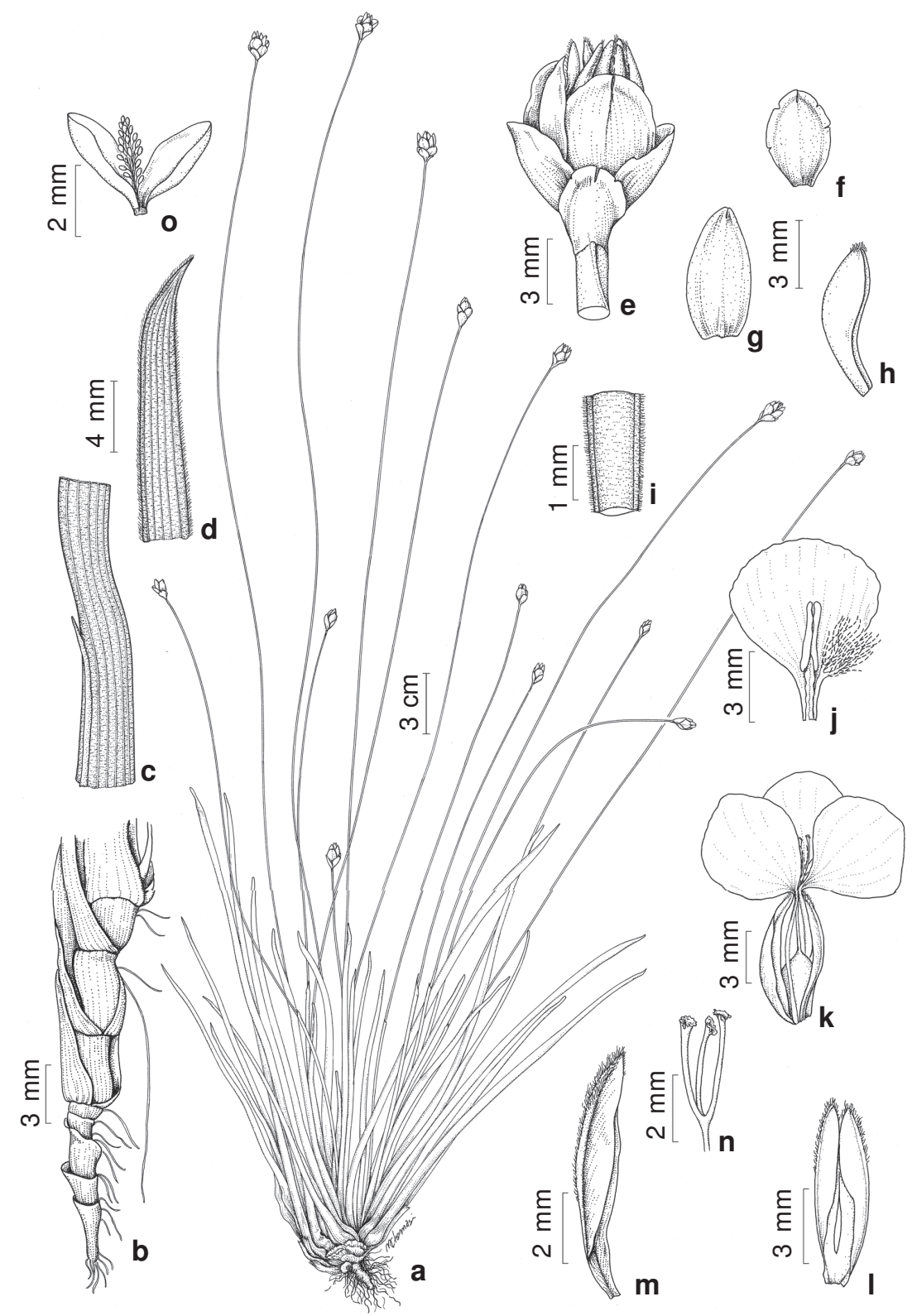

Figura 4 - Xyris nanuzae - a. hábito; b. rizoma vertical, com entrenós alongados; c. detalhe do ápice da bainha, mostrando lígula e superfície conspicuamente nervada; d. ápice da folha, com margem ciliada, superfície nervada e ápice agudo e falciforme; e. espiga; f-g. brácteas estéreis; h. bráctea floral vista lateralmente, com ápice ciliadofimbriado; i. detalhe da parte superior do escapo; j. detalhe do lobo da corola orbicular, estame e estaminódio; k. flor completa, com bráctea floral, sépalas laterais, corola, androceu e gineceu; 1. sépalas laterais concrescidas, mostrando carena ciliada; $m$. detalhe da sépala destacada, com carena conspicuamente ciliada; $n$. ápice do estilete com os três ramos e estigmas expandidos; o. fruto aberto, mostrando placentação central-livre com eixo delicado (a Kral 72940, b-o Wanderley CFSC 5614).

Figura 4 - Xyris nanuzae - a. habit; b. vertical rhizome, with enlarged internode; c. sheath apex detail, with ligule and costate surface, d. leaf apex, with ciliate margin, costate surface and acute falciform apex; e. spike; f-g. sterile bracts; h. floral bract, lateral view, note ciliate-fimbriate apex; i. detail of scape apex; j. detail of the orbicular corolla lobe, stamen and staminodia; k. complete flower, with floral bract, lateral sepals, corolla, androecium and gynoecium; 1. lateral sepals connate; m. sepal detail, with broad ciliate keel; n. style apex with three expanded branches and stigmas; o. open capsule, with central-free placentation and delicate axis (a Kral 72940, b-o Wanderley CFSC 5614). 

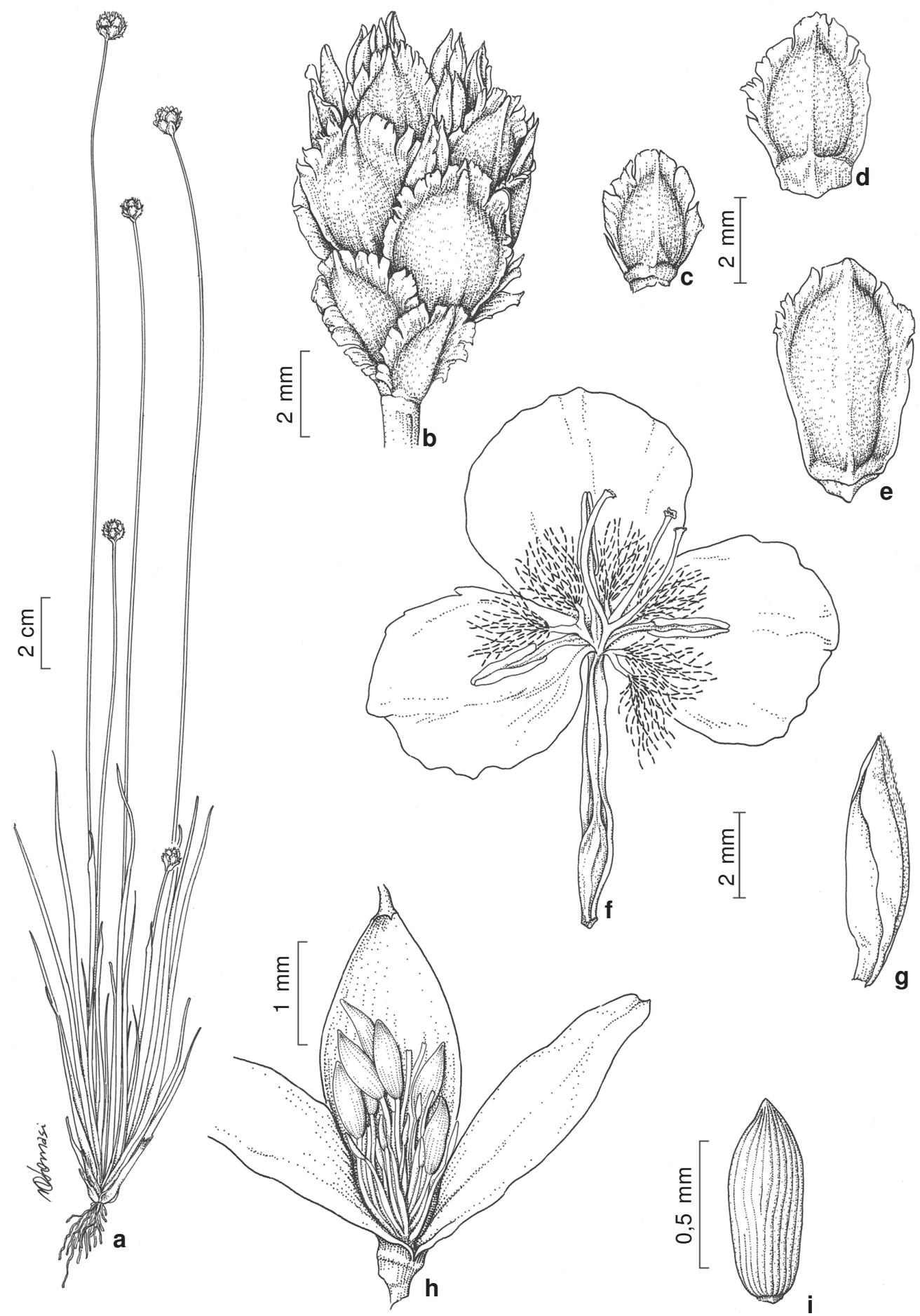

Figura 5 -Xyris piranii - a. hábito; b. espiga; c-d. brácteas estéreis; e. bráctea floral; f. flor aberta sem as sépalas, com pétalas, androceu e gineceu; g. sépala lateral livre; h. fruto, mostrando placentação basal e sementes com funículos longos; i. semente (Wanderley CFSC 5478).

Figura 5 -Xyris piranii - a. habit; b. spike; c-d. sterile bracts; e. floral bract; f. open flower without sepals, showing petals, androecium and gynoecium; g. lateral sepal free; h. capsule, basal placentation and long funicule seeds; i. seed (Wanderley CFSC 5478). 
inconspícua, membranácea; lâmina linear, achatada, 2,6$6 \times 0,1-0,2 \mathrm{~cm}$, pouco mais estreita na transição para a bainha, ápice atenuado, superfície estriada. Espata conduplicada, com lâmina curta, ca. 2 mm compr. Escapo 20-30 cm compr, cilíndrico, ca. 1,5 mm larg. Espiga ca. 10 flores, globosa, ca. $7 \times 6-7 \mathrm{~mm}$, eixo da inflorescência curto, ca. $2 \mathrm{~mm}$ compr.; brácteas estéreis 4 , triangulares a ovadas, 4-5 $\times 2-3 \mathrm{~mm}$, castanho-escuras a negras, concolores, rugulosas, carena inconspícua, margem lacerada; brácteas florais semelhantes às brácteas estéreis, ovadas a obovadas, 5,5-6,5×3,5-4 mm; sépala anterior coriácea, avermelhada; sépalas laterais exsertas, livres, lanceoladas, ca. $6 \mathrm{~mm}$ compr., inequilaterais, carena ciliado-fimbriada; pétalas ca. 1,2 cm compr., lobo orbicular, ca. $5 \times 4 \mathrm{~mm}$; estaminódios pilosos, subsésseis; estames ca. 2,5 mm compr., antera sagitiforme, amarela; estilete ca. $7 \mathrm{~mm}$, ramos ca. $3 \mathrm{~mm}$ compr, estigma truncado. Placentação basal. Cápsula ovóide, ca. 4 mm compr; sementes ca. $8 \mathrm{~mm}$ compr., estriadas.

Material examinado: BRASIL. MINAS GERAIS: Santana do Riacho, rodovia Belo Horizonte-Conceição do Mato Dentro, km 136, 4.VII.1978, M.G.L. Wanderley CFSC 5484 (SP); km 137, 5.VII.1978, fl., M.G.L. Wanderley CFSC 5499 (SP);km 132, 1.VIII.1988,R. Kral 72986A (SP); Parque Nacional da Serra do Cipó, km 139-140, 5.VII.1989, M.G.L. Wanderley et al. CFSC 11566 (SP).

O epíteto específico foi dado em homenagem ao Dr. José Rubens Pirani, atual coordenador da Flora da Serra do Cipó e formador de vários taxonomistas em famílias ocorrentes na região.

Espécie conhecida até o momento apenas para a Serra do Cipó, Minas Gerais. Os materiais coletados na região apresentaram floração e frutificação entre os meses de julho e agosto.

Xyris piranii é bem distinta das demais espécies ocorrentes na Serra do Cipó, sendo facilmente reconhecida pelas folhas com ápice atenuado, espigas pequenas e globosas, com brácteas castanho-escuras a quase negras e margens fortemente laceradas, sépalas livres e placentação basal. As brácteas com margem lacerada também são observadas em X. schizachne Mart., porém, nesta espécie, a margem é retroflexa e avermelhada, características não observadas em $X$. piranii.

\section{Agradecimentos}

Ao Conselho Nacional de Desenvolvimento Científicoe Tecnológico(CNPq)a Bolsa de Produtividade concedida; à Suzana Martins a revisão do texto, ao
Dr. Tarciso Filgueiras a versão das diagnoses para o Latim; e aos coordenadores do Projeto Flora da Serra do Cipó, Dr. José Rubens Pirani (atual) e a Dra. Ana Maria Giulietti (início do projeto).

\section{Referências}

Campbell, L.M. 2004. Anatomy and Systematics of Xyridaceae, with special reference to Aratitiyopea Steyerm. \& P.E. Berry. Doctoral thesis. City University of New York, New York. Pp. 1-182.

Campbell, L.M. 2005. Contribuitions towards a monograph of Xyridaceae: A Revised Nomenclature of Abolboda. Harvard Papers in Botany 10: 137-145.

Campbell, L.M.; Wanderley, M.G.L. \& Silva, G.S. 2009. Xyridaceae. In: Neotropikey. Version 1. Royal Botanic Gardens, Kew. Disponível em<http://www.kew.org/ science/tropamerica/neotropikey.htm>. Acesso em abril 2010.

Giulietti, A.M. \& Pirani, J. R. 1988. Patterns of geographic distribution of some plant species from the Espinhaço Range, Minas Gerais and Bahia, Brazil. In: Vanzolini, P.E. \& Meyer, W.R. (eds.). Proceedings of a workshop of neotropical distribution patterns. Academia Brasileira de Ciências, Rio de Janeiro. Pp. 39-69.

Giulietti, A.M.; Menezes, N.L.; Pirani, J.R.; Meguro, M. \& Wanderley, M.G.L. 1987. Flora da Serra do Cipó, Minas Gerais: caracterização e lista das espécies. Boletim de Botânica da Universidade de São Paulo 9: 1-151.

Giulietti, A.M.; Wanderley, M.G.L.; Longhi-Wagner, H.M.; Pirani, J.R. \& Parra, L.R. 1996. Estudos em "semprevivas": taxonomia com ênfase nas espécies de Minas Gerais, Brasil. Acta Botanica Brasilica 10: 329-376.

Kral, R. 1988. The genus Xyris (Xyridaceae) in Venezuela and contiguous Northern South America. Annals of the Missouri Botanical Garden 75: 522-722.

Mendonça, M.P. \& Lins, L.V. 2000. Lista Vermelha das Espécies Ameaçadas de Extinção da Flora de Minas Gerais. Biodiversitas \& Fundação Zoo-Botânica de Belo Horizonte, Belo Horizonte. Pp. 1-157.

Smith, L.B. \& Downs, R J. 1968. Xyridaceae. In: Hoehne, F.C. \& Teixeira, A.R. (eds.). Flora Brasilica. Instituto de Botânica, São Paulo. Vol.9(2), fasc. 12. Pp.1-42.

Wanderley, M.G.L.1992. Estudos taxonômicos no gênero Xyris L. (Xyridaceae) da Serra do Cipó, Minas Gerais, Brasil. Tese de Doutorado. Universidade de São Paulo, São Paulo. 405p.

Wanderley, M.G.L. 2003. Xyridaceae. In: Wanderley, M.G.L.; Shepherd, G.J.; Giulietti, A.M. \& Melhem, T.S. (ed.). Flora Fanerogâmica do Estado de São Paulo. Instituto de Botânica, São Paulo. Vol. 3. Pp. 333-348.

Wanderley, M.G.L. \& Silva, M.B.C. 2009. Flora de GrãoMogol, Minas Gerais: Xyridaceae. Boletim de Botânica da Universidade de São Paulo 27: 137-147. 